\title{
O ESTUDO DO PRÉ-CÁLCULO NA EDUCAÇÃO A DISTÂNCIA MEDIANTE CONEXÕES COM PROBLEMAS REAIS
}

\author{
CURITIBA/PR MAIO/2018
}

\author{
Ricardo Alexandre Deckmann Zanardini - Uninter - ricardo.z@uninter.com \\ Fernanda Fonseca - Uninter - fernanda.f@uninter.com \\ Ederson Cichaczewski - Uninter - ederson.c@uninter.com \\ Edson Pedro Ferlin - Uninter - edson.f@uninter.com
}

\author{
Tipo: Relato de Experiência Inovadora (EI) \\ Categoria: Métodos e Tecnologias \\ Setor Educacional: EDUCAÇÃO SUPERIOR
}

\begin{abstract}
RESUMO
Mesmo em uma sociedade onde a comunicação e a tecnologia apresentaram recentes avanços bastante significativos, o estudo da matemática ainda é algo que para a maioria dos professores e estudantes é algo abstrato, desmotivador e distante da realidade. Em relação à disciplina de Précálculo, as obras e o material didático existentes são amplamente teóricos e na maioria dos casos não apresentam exemplos de aplicações em situações reais. Com o objetivo de apresentar os temas dessa disciplina de maneira motivadora e útil aos estudantes, todo o material didático da disciplina ofertada para os cursos a distância de Engenharia da Computação, Engenharia Elétrica e Engenharia de Produção de uma grande instituição de ensino superior com sede em Curitiba. A verificação dos resultados decorrentes dessa escolha foi feita de forma qualitativa mediante a análise das interações com estudantes e outros professores. No estudo fica evidente que a motivação e a postura dos estudantes em relação aos estudos são bastante inspiradoras quando o estudo é feito de forma tradicional e desprovida de aplicações e de relações com situações do cotidiano dos estudantes.
\end{abstract}

Palavras-chave: aplicações, educação a distância, pré-cálculo 


\section{INTRODUÇÃO}

Visando a democratização do ensino, a Educação à Distância (EAD) se estabelece de forma crescente no Brasil após a implantação da Lei de Bases e Diretrizes da Educação Nacional de 1996, que aprova a modalidade de Educação à Distância em todos os níveis e modalidades de ensino, e de educação continuada (BRASIL, 1996). Uma modalidade que possibilita atingir às classes marginalizadas da sociedade que não tiveram acesso à educação (MARTINS, 2008), atendendo um público de diferentes regiões e países. Diante do amplo e distinto público, há assim a necessidade de definição dos objetivos formativos dos cursos, visando contribuir ao desenvolvimento da sociedade (MUGNOL, 2009).

Entretanto, no final do século $X X$ a expansão de estudos gerou a apresentação de vários projetos fragmentados, sem coerência e com intenções conflitantes com os objetivos educacionais, que tratavam os conteúdos de forma superficial dando maior atenção ao uso de novas tecnologias. No início do século seguinte que instituições de ensino brasileiras criaram grupos de investigação e divulgação de pesquisas sobre a EAD, e buscaram a implementação de projetos de formação continuada que desencadearam um repensar dos processos organizadores da aprendizagem que incluíram o uso de novas tecnologias de informação e de comunicação (MARTINS 2008).

Para Martins (2003), com a expansão das formas de comunicação e a ampliação ao aceso à informação, a sociedade rompeu com a concepção de sociedade industrial e fordista, tornando-se uma sociedade da informação e do conhecimento que se baseia "no aumento da produtividade, na modernização dos métodos de gestão, nas novas tecnologias [...], na alta velocidade de decisões e no aumento da capacidade criativa" (MARTINS, 2003, p. 2). Uma visão em que o conhecimento é um recurso social a ser convertido em capital intelectual e que exige uma constante atualização, ou seja, estabelece a necessidade de formação continuada diante do sentimento de obsolescência.

Por sua vez, esse modelo social não é representado pela didática tradicional, em que o professor é o protagonista principal do processo de ensino-aprendizagem. A EAD leva então à reflexão sobre modelos pedagógicos transgressores (MARTINS, 2008), buscando metodologias que preservem o compromisso da universidade com a qualidade de ensino e a responsabilidade social, ampliando "o universo do desenvolvimento de práticas que correspondam ao ritmo, à velocidade e à exigência de perfil do profissional" (MARTINS, 2003, p. 3). 
A adoção de uma metodologia de interação mediada por um professor-tutor, ou seja, de orientador da aprendizagem que estabelece uma relação que vai além da interação professor-aluno, visando um aprendizado baseado na integração e na colaboração, independentemente do tempo e do espaço. A EAD apresenta um processo de ensinoaprendizagem que deve propor reflexão e questionamento, levando o estudante a buscar por novas perspectivas do objeto de estudo e do conhecimento. Para tal, o professor deve selecionar os conteúdos priorizando "os temas significativos para reflexão, a análise e a produção de conhecimentos novos" (MARTINS, 2003, p. 5) de forma problematizadora, visando os objetivos formativos políticos, técnicos e profissionais, direcionando o desenvolvimento de competências e habilidades de pensamento abstrato, lógico e formal. Em outras palavras, o professor deve preparar suas aulas tendo em vista que o processo de ensino-aprendizagem deve promover uma qualificação autônoma, crítico-reflexiva e técnica do profissional, assim como o desenvolvimento da cidadania. Essa nova concepção de ensino está atrelada aos fins para o qual se destina o saber.

A educação a distância pode ser compreendida como um processo de ensino bidirecional que, segundo Martins (2008), estabelece uma relação entre professor, aluno e instituição de ensino proporcionando as condições necessárias para a ocorrência da aprendizagem. Para Mugnol (2009), a EAD é um processo estudo pessoal e individual, mas que estabelece um diálogo com instrutores (fluxo bidirecional) e que utiliza formas de comunicação independentes do tempo e do espaço.

Essa metodologia, por sua vez, exige uma maior responsabilidade do aluno sobre sua própria formação, requerendo maturidade intelectual para estudos individuais e disciplina para cumprir as tarefas propostas. Por isso, é de suma importância promove a conscientização do estudante sobre seus deveres para com os resultados da sua aprendizagem. Para tal, é necessária a criação de oportunidades e meios para que a aprendizagem ocorra (MUGNOL, 2009).

Segundo Martins (2008), é preciso o desenvolvimento de uma metodologia não reprodutiva, em que o aluno não atua de forma passiva. "As informações não podem só ser repassadas por máquinas" (MARTINS, 2008, p. 264), elas devem ser problematizadas, levando o aluno a pesquisar, refletir e questionar, sob a orientação dos professores-tutores.

Outro ponto a ser destacado é a EAD é fundamentalmente direcionada a formação de adultos, para os quais a aprendizagem é concebida mais como um meio que como finalidade (MARTINS, 2003). Isso porque o adulto precisa que as experiências de 
aprendizagem sejam úteis para resolver problemas cotidianos, para enfrentar mudanças, ou para gerar mudanças em sua vida. A tensão das dificuldades enfrentadas pelos adultos estimula a sua aprendizagem (MARTINS, 2003). Mas é importante considerar os diferentes estilos cognitivos dos sujeitos (MUGNOL, 2009). A interação com o professor tutor da EAD permite assim a composição de um processo de ensino aprendizagem de acordo com as necessidades do estudante como indivíduo.

$\mathrm{Na}$ elaboração do material didático para disciplina de Pré-cálculo de uma grande instituição de ensino do Brasil na modalidade EAD esses fatores foram considerados.

Atualmente o ensino do Pré-cálculo é feito na maioria das vezes de forma abstrata e conceitual com poucas aplicações relacionadas a problemas do cotidiano dos estudantes, o que torna desprovido de sentido o estudo da disciplina.

\section{APLICAÇÕES DO PRÉ-CÁLCULO EM PROBLEMAS REAIS}

É muito comum estudantes e profissionais acreditarem que conhecimentos matemáticos não possuem utilidades práticas e que temas estudados não possuem conexões com situações reais. Em particular, no caso do Pré-cálculo, essa sensação é agravada devido ao fato de que nas obras existentes é feita uma abordagem teórica e conceitual desprovida de quaisquer exemplos práticos. As aulas tradicionais seguem esse mesmo modelo. Teoria e séries de exercícios de aprendizagem quase que na maioria abstratos e desmotivadores. São atividades enfadonhas e desprovidas de percepções de possíveis conexões com a realidade.

A partir de determinados conceitos da matemática, é possível fazer contagens, estudar o crescimento de populações, determinar a quantidade ideal de ingestão de um medicamento, determinar o preço que fornece a maior receita possível de uma determinada mercadoria, calcular o valor referente a uma ação trabalhista, planejar a produção de uma indústria, realizar processamento digital de sinais e de imagens, desenvolver sistemas cada vez mais modernos que permitem a comunicação entre as pessoas, além de muitas outras aplicações importantes. O funcionamento de um computador, de um telefone celular ou de uma máquina de tomografia computadorizada, por exemplo, baseiam-se em importantes temas da matemática tais como funções, logaritmos, sistemas de equações, funções trigonométricas, além de outros.

A matemática está presente em praticamente todos os eventos do nosso cotidiano. A 
sua história está diretamente relacionada com a história da humanidade. Segundo Zanardini (2017), os temas estudados em Pré-cálculo surgiram ao longo dos séculos, a partir de situações concretas relacionadas à agricultura, comércio, economia e engenharia. $O$ progresso da matemática primitiva acompanhou o crescimento e a evolução da sociedade da época (ZANARDINI 2017). No entanto, a partir dos séculos XVII e XVIII a matemática tomou novos rumos. A partir desse período tem-se o início da matemática avançada. Os estudos abordam conceitos matemáticos mais abstratos e conceituais, mas mesmo assim são extremamente úteis e aplicáveis. O funcionamento de um computador, por exemplo, baseia-se em operações matemáticas e nos números 0 e 1. A partir dessas operações elementares e de apenas dois números, é possível criar um universo imensurável de possibilidades. Dados são processados, textos, imagens, áudio e vídeo são criados e compartilhados facilmente. Mas se a matemática é tão importante e diretamente relacionada ao cotidiano das pessoas, surge uma pergunta: por que muitas pessoas apresentam dificuldades no estudo e na compreensão de temas pertencentes a essa ciência? Devlin (2004) afirma que todas as pessoas são capazes de aprender matemática e o que facilita ou dificulta a aprendizagem para determinadas pessoas é a capacidade de abstração.

Abordar os temas e relacionar com situações é um diferencial que auxilia na compreensão e no melhor aproveitamento. Infelizmente essa abordagem não é usual nas obras existentes e, consequentemente, nos cursos de Pré-cálculo.

Com o intuito de obter melhorias no processo de aprendizagem, a cada tema da disciplina de Pré-cálculo, além dos aspectos teóricos e conceituais, foram apresentadas também aplicações. A seguir alguns exemplos das aplicações associadas aos principais temas estudados na disciplina.

No Século VI a.C., um importante matemático grego, Pitágoras, desenvolveu vários estudos importantes para o desenvolvimento da matemática. Uma de suas redescobertas foi a relação métrica entre os lados de um triângulo retângulo. Se elevarmos ao quadrado a medida do maior lado do triângulo retângulo (hipotenusa), o resultado será igual à soma dos quadrados das medidas dos lados menores do triângulo (catetos). Essa observação deu origem ao famoso teorema de Pitágoras: $a^{2}+b^{2}=c^{2}$. Na construção civil, por exemplo, um pedreiro pode saber se duas paredes estão formando um ângulo reto ou não. Marcando em uma das paredes um ponto 60 centímetros distante do canto e na outra parede um ponto cuja distância em relação ao canto é de 80 centímetros, a medida entre eles deve ser igual a 1 metro (100 centímetros). Isso é possível por que os números 60, 80 e 100 correspondem aos lados de um triângulo retângulo. 
Quando o assunto é intervalo numérico, em uma pesquisa que mede as intenções de voto de um candidato, por exemplo, é muito comum termos uma margem de erro em função da amostra escolhida. Por exemplo, se um candidato tem $55 \%$ das intenções de voto com uma margem de erro de $2 \%$ para mais ou para menos, na verdade, as intenções de voto desse candidato variam de $53 \%$ a $57 \%$. É só calcularmos $55 \%-2 \%=$ $53 \%$ e $55 \%+2 \%=57 \%$. Podemos escrever esse intervalo utilizando desigualdades:

$53 \%<=x<=57 \%$

onde $\mathrm{x}$ indica a porcentagem de intenções de voto desse candidato.

Em relação à potenciação, uma das aplicações está na matemática financeira. É possível calcular o valor de um capital acrescido de juros utilizando a potenciação. Se uma pessoa tem uma aplicação no valor de $R \$ 1.676,30$, feita por um período de 10 meses com juros compostos de $16 \%$ ao mês, o total dessa aplicação é calculado por meio da fórmula $M=C \cdot(1+i)^{n}$ :

$M=1676,30 \cdot(1+0,16)^{10}$

$M=1676,30 \cdot(1,16)^{10}$

$M=1676,30 .(4,411435079)$

$M=7394,89$

A operação inversa à potenciação é a radiciação que também tem aplicações na matemática financeira. É possível calcular a taxa de juros de uma aplicação

Quando a fórmula quadrática, também conhecida como fórmula de Bháskara, é muito comum haver um questionamento por parte dos estudantes em relação às aplicações dessa fórmula. Como o objetivo é determinar, caso existam, as intersecções do gráfico da função com o eixo das abscissas, uma das aplicações é a determinação do preço de venda de uma determinada mercadoria de modo que o lucro referente às vendas seja maior do que zero.

Para isso, basta saber qual é a função que relaciona o preço de venda com o lucro e em seguida determinar as raízes $\mathrm{x}_{1}$ e $\mathrm{x}_{2}$ que correspondem aos preços onde o lucro é igual a zero. Também é possível saber qual é o preço que maximiza o lucro, para quais preços o lucro é crescente, para quais é decrescente e muito mais. 
É claro que existem muito mais aplicações reais para esses e para os outros temas das disciplinas.

\section{A CONTEXTULIZAÇÃO E A MOTIVAÇÃO DOS ESTUDANTES}

O material de Pré-cálculo foi elaborado para os estudantes dos cursos de Engenharia da Computação, Engenharia de Produção e Engenharia Elétrica, na modalidade a distância, de uma instituição de ensino superior de Curitiba. O material didático é composto de rotas de aprendizagem contendo contextualização, teoria, exemplos de aplicações, vídeos, exemplos resolvidos e exercícios e atividades pedagógicas a serem realizadas pelos estudantes. O suporte aos alunos é feito por meio da tutoria localizada em cada pólo de apoio presencial. O estudante também pode participar de chats e enviar dúvidas, comentários e sugestões para o professor da disciplina que, no ambiente virtual, está em contato diário com os alunos. As dúvidas são esclarecidas por meio de vídeos personalizados produzidos para cada estudante que entra em contato. Também há um fórum que conta com a participação de estudantes e professores e o incentivo à formação de grupos de estudo. Uma outra possibilidade é que a cada nova oferta da disciplina, os alunos podem interagir com o professor durante as três aulas ao vivo destinadas à resolução de exercícios e que têm como objetivo esclarecer de forma geral dúvidas que surgem durante o período de oferta da disciplina. Toda essa estrutura visa complementar e solidificar o trabalho desenvolvido, bem como oferecer o melhor suporte possível aos estudantes. As atividades e as avaliações seguem a mesma linha de trabalho das aulas e abordam, além dos aspectos teóricos, as aplicações do Pré-cálculo em problemas reais.

Para verificar a efetividade da abordagem utilizada na disciplina de Pré-cálculo, optou-se por uma pesquisa qualitativa onde o objetivo maior é a valorização dos fatos e a verificação da realidade como ela acontece. Para compor esse trabalho, foram analisadas as interações com os estudantes, as participações nos chats, no canal de tutoria, comentários enviados pelos alunos e por outros professores e tutores.

É possível perceber que a receptividade por parte dos estudantes e o respectivo desempenho são melhores do que o observado em outros ambientes onde o ensino do Pré-cálculo é feito de forma abstrata e desprovido de aplicações.

Tanto no canal de tutoria quanto nos chats e fóruns, os comentários dos estudantes demonstram a satisfação em estudar e conhecer a importância e as aplicações reais dos 
temas estudados. Dentre diversos comentários, alguns retratam de maneira efetiva a receptividade e a satisfação dos estudantes: "Estudei sobre conjuntos numéricos, intervalos numéricos, potenciação e radiciação e embora já tivesse visto esse assunto antes foi muito proveitoso rever o assunto e ainda ver como ele pode ser aplicado na pratica, algo útil e mais fácil de aprender que um conteúdo somente teórico.", "Uma grande diferença desse curso é que vamos aplicar a matemática na prática. Diferente da forma exaustiva como sempre foi ensinado nos anos escolares. Isso nos proporciona uma grande vantagem na aprendizagem.", "Muito feliz participando desta disciplina", "O curso realmente me surpreendeu positivamente. Qualidade de material, docência, estrutura, tudo. Estão de parabéns.", "Aulas muito bem elaboradas.".

Como aplicações são abordadas na disciplina, também é comum os estudantes postarem dúvidas relacionadas a problemas que aparecem no cotidiano deles: "Bom dia, eu gostaria que o senhor me ajudasse no seguinte problema pra formular e obter a função: no meu trabalho existe um rede de comunicação a dois fios que percorrem praticamente todos os equipamentos automatizados e nele percorre uma corrente de 4 miliamperes $\left(4 \times 10^{\wedge}(-3)\right)$ a 20 miliamperes $\left(20 \times 10^{\wedge}(-3)\right)$. Na sala de controle existe um controle que trabalha nesse range: 4/0\% e 20/100\%. Se eu pedir por exemplo: Abrir uma válvula em $22 \%$, se eu colocar meu alicate de amperímetro lá no local, quanto deverá ter, em miliamper, e o mais importante, qual será a função utilizada?".

É evidente que a satisfação e a motivação dos estudantes são bastante positivas. No entanto é importante ressaltar que isso não reduz o número de dúvidas e de questionamentos em relação aos temas. Pelo contrário, acaba gerando uma grande participação dos estudantes que demonstram interesse em aprender de uma forma mais efetiva o que estão estudando.

\section{CONSIDERAÇÕES FINAIS}

Em um mundo onde a comunicação está amparada pelos avanços tecnológicos e consequentemente cada vez mais fácil e abrangente, o acesso à informação é mais evidente. $\mathrm{Na}$ atualidade, mais importante do que ter informações é saber o que fazer com as informações. Com um computador ou um smartphone e com acesso à internet as pessoas possuem um acervo gigantesco de conteúdos. Ter uma postura crítica para selecionar os assuntos realmente relevantes e utilizar essas informações para melhorar atitudes e procedimentos é fundamental na sociedade. Em decorrência da demanda atual, a disciplina de Pré-cálculo foi elaborada de forma inovadora e diferenciada 
apresentando relações dos principais temas da matemática elementar com situações reais dos estudantes e da sociedade. Diante dessa abordagem é bem claro que a postura dos estudantes e a motivação em relação aos estudos, à interação com professores e com estudantes e à visão da necessidade de ter o conhecimento em relação a determinados assuntos e em saber o que fazer com esses conhecimentos é melhor do que a postura passiva e apática quando é preciso estudar temas que não apresentam as respectivas relações com o cotidiano dos estudantes.

\section{REFERÊNCIAS}

BRASIL. Lei de Diretrizes e Bases da Educação Nacional. Lei ㄲo. 9.394/96, 20 de dezembro de 1996.

DEVLIN, K. O gene da matemática. Rio de Janeiro, Record, 2004.

MARTINS, O. B. Teoria e prática tutorial em educação à distância. Educar em Revista, n. 21, Curitiba, Editora UFPR, 2003. p. 1-19.

MARTINS, O. B. Os caminhos da EAD no Brasil. Revista Diálogo Educacional, v. 8, n. 24, mai-ago/2008. p. 357-371.

MUGNOL, M. A educação à distância no Brasil: conceitos e fundamentos. Revista Diálogo Educacional, v. 9, n. 27, mai-ago/2009. p. 335-349.

ZANARDINI, R. A. D. Um breve olhar sobre a história da matemática. Curitiba, Intersaberes, 2017. p. 21-22. 